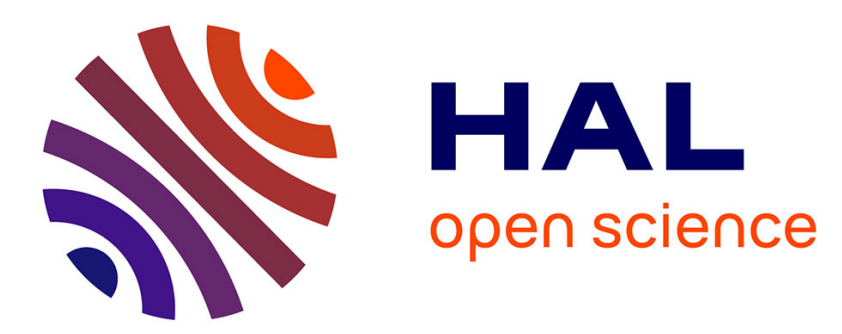

\title{
Solvents with Similar Bulk Properties Induce Distinct Supramolecular Architectures
}

Thomas Pinault, Benjamin Isare, Laurent Bouteiller

\section{To cite this version:}

Thomas Pinault, Benjamin Isare, Laurent Bouteiller. Solvents with Similar Bulk Properties Induce Distinct Supramolecular Architectures. ChemPhysChem, 2006, 7 (4), pp.816-819. 10.1002/cphc.200500636 . hal-01696736

\section{HAL Id: hal-01696736 https://hal.science/hal-01696736}

Submitted on 29 Aug 2020

HAL is a multi-disciplinary open access archive for the deposit and dissemination of scientific research documents, whether they are published or not. The documents may come from teaching and research institutions in France or abroad, or from public or private research centers.
L'archive ouverte pluridisciplinaire HAL, est destinée au dépôt et à la diffusion de documents scientifiques de niveau recherche, publiés ou non, émanant des établissements d'enseignement et de recherche français ou étrangers, des laboratoires publics ou privés. 


\section{Solvents with similar bulk properties induce distinct supramolecular architectures}

Thomas Pinault, Benjamin Isare, and Laurent Bouteiller*

T. Pinault, Dr. B. Isare, and Dr. L. Bouteiller*

Laboratoire de Chimie des Polymères, UMR 7610 CNRS - Université Pierre et Marie Curie, 4 place Jussieu, 75252 Paris Cedex 05, France.

Learning how to use external stimuli to tune the structure of supramolecular assemblies is particularly desirable, as it should create new opportunities to build functional nanomaterials. In this respect, the most popular stimuli are temperature, ${ }^{[1]} \mathrm{pH}^{[2]}{ }^{[i g h t}{ }^{[3]}$ and red-ox chemistry. ${ }^{[4]}$ In contrast, the nature of the solvent is usually considered to be of minor importance, although some well known effects have been demonstrated, such as the influence of polarity ${ }^{[5]}$ or self-assembly driven by solvophobic interactions. ${ }^{[6]}$ In fact, there are only few examples of supramolecular structures that are significantly influenced by a minor change in the solvent, such as its molecular shape or size. ${ }^{[7]}$ Here, we report that the supramolecular structure formed by a simple hydrogen bonded compound can be triggered by a subtle change of the solvent.

Bis-urea EHUT (Scheme 1) was previously reported to self-assemble into either thin or thick filaments in toluene solutions. ${ }^{[8]}$ Figure 1a recalls the pseudo-phase diagram, which indicates the temperature and the concentration domains where each assembly is stable. The thin filaments formed at high temperatures were unambiguously shown by small angle neutron scattering (SANS) to be monomolecular chains of hydrogen bonded bis-ureas, but the room temperature stable, thick filament structure could not be precisely ascertained. ${ }^{[8]}$ Two different structures, that are in agreement with SANS data, were proposed: a compact cylindrical structure with 2 bis-urea molecules in the cross-section, or a tube-like structure with 3 bis-urea molecules in the cross-section. The latter structure is particularly intriguing, because simple molecular mechanics simulations show that if such a structure is actually 
formed, then a central cavity, large enough to accommodate toluene molecules, is created within the tube (Figure 2). Consequently, if we assume that this trimolecular structure is indeed formed in toluene, then a strong solvent effect can be expected. Indeed, a solvent that is too bulky to fit inside the tube should necessarily destabilise the thick filament structure. Thus, we investigated a range of aromatic solvents of very similar structures and properties, but of distinct molecular sizes.

Since the thick filament structure has been shown to yield solutions of much higher viscosity than the thin filament, a simple visual test was first used: Figure 3 qualitatively shows that the macroscopic properties of EHUT solutions depend markedly on the nature of the solvent. It takes less than a second after test tube inversion, for the solution in 1,3,5trimethylbenzene (TMB) to flow, but it takes about 1 hour for solutions in toluene or $t$ butylbenzene to flow completely. ${ }^{[9]}$ To confirm that this phenomenon is related to structural differences, the pseudo-phase diagram of EHUT in TMB was determined (Figure 1b). The assignment of the structures is based on FTIR spectroscopy, because the shape of the hydrogen bonded N-H band was previously shown ${ }^{[8]}$ to be characteristic of each structure (see spectra in Supporting Information). The present results show that, at room temperature, EHUT self-assembles into thin filaments in TMB, but into thick filaments in toluene, which explains the large viscosity difference of the corresponding solutions. The important question is of course to know why there is such a large structural difference in these two solvents. In this respect, it is interesting to note that only the transition between the thin and thick filament is shifted (by $30^{\circ} \mathrm{C}$ ); the transition between the monomer and the thin filament is almost not affected (Figure 1). This shows that the strength of hydrogen bonds is similar in these two solvents (as expected from their similar dielectric constants). In order to find some kind of correlation between the stability of the thick filament and a solvent characteristic, the transition temperature between the thin and thick filaments $\left(\mathrm{T}^{* *}\right)$ was systematically measured by FTIR (Table 1 and Supporting Information). All the solvents tested have very similar dielectric constants (between 2.2 and 2.6) and dipole moments (lower than $0.5 \mathrm{D}$ ), and there is no correlation between these quantities and $\mathrm{T}^{* *}$ (see Supporting Information). In contrast, Figure 4 shows that there is a clear correlation between the solvent molecular width 
(W) and T**.[11] Apparently, the largest dimension (the length L) of the solvent molecule has no influence on the transition temperature, but the second largest dimension (the width $\mathrm{W}$ ) has a strong influence: the "slim" solvents $(\mathrm{W} \leq 7.0 \AA)$ yield the most stable thick filaments $\left(\mathrm{T}^{* *}\right.$ $\geq 40^{\circ} \mathrm{C}$ ), while the "fat" solvents $(\mathrm{W} \geq 7.7 \AA)$ yield the least stable thick filaments $\left(\mathrm{T}^{* *} \leq\right.$ $25^{\circ} \mathrm{C}$ ). These geometrical characteristics indicate that a steric fit between the thick filament and the solvent molecules is necessary for the filament stability. Analogous geometrical constraints are well known in the field of host-guest systems based on self-assembled capsules. ${ }^{[12]}$ In the present case, the fact that we could not find a limiting length for the solvent molecule, but only a limiting width, argues favourably for a tubular cavity rather than a spherical one; in line with a structure such as represented on Figure 2.

In conclusion, we have shown that bis-urea EHUT displays markedly different properties when dissolved in a range of apparently similar aromatic solvents. These different properties are due to the relative stability of low viscosity thin filaments and high viscosity thick filaments formed by EHUT. This relative stability is in turn related to the steric complementarity between the solvent molecules and the thick filaments. Although these data do not constitute a direct proof for the proposed thick filament tubular structure (Figure 2), they are in very good agreement with such a structure. Finally, if the formation of the tubular and thermodynamically stable architecture proposed on Figure 2 is confirmed by further studies, it opens up new opportunities in the field of host-guest chemistry, because of the unusual shape of the expected cavity and because of the chemical accessibility of EHUT.

\section{Experimental Section}

The synthesis of EHUT was described previously. ${ }^{[10]}$ All solvents were obtained from Aldrich and used without further purification. The solutions were prepared by shaking weighted amounts of EHUT and solvents at room temperature. Heating accelerated the dissolution process, but did not alter the final properties of the solutions at room temperature. Unlike classical organogelators, ${ }^{[13]}$ these viscoelastic solutions are thermodynamically stable. 
IR spectroscopy. Infrared spectra were recorded on a Nicolet Avatar 320 spectrometer in a $\mathrm{KBr}$ cell of $0.1 \mathrm{~cm}$ path length. The temperature was controlled with a heating device (P/N21525) from Specac. Consecutive measurements were separated by at least 10 minutes, to allow for thermal equilibration. Thermal expansion of the solutions was not corrected. The transition temperatures $\left(\mathrm{T}^{* *}\right)$ were determined as previously described. ${ }^{[8]}$

ITC. Heats of dissociation were measured using a MicroCal VP-ITC titration microcalorimeter. The experimental conditions have been described previously. ${ }^{[14]}$

\section{Acknowledgements}

S. Canaguier and A. Servant are thanked for their contribution to this project.

[1] S. Kiyonaka, K. Sugiyasu, S. Shinkai, I. Hamachi, J. Am. Chem. Soc. 2002, 124, 10954; S. Valkama, H. Kosonen, J. Ruokolainen, T. Haatainen, M. Torkkeli, R. Serimaa, G. Ten Brinke, O. Ikkala, Nature Materials 2004, 3, 872; J. H. van Esch, B. L. Feringa, Angew. Chem. Int. Ed. 2000, 39, 2263; Angew. Chem. 2000, 112, 2351.

[2] A. Aggeli, M. Bell, L. M. Carrick, C. W. G. Fishwick, R. Harding, P. J. Mawer, S. E. Radford, A. E. Strong, N. Boden, J. Am. Chem. Soc. 2003, 125, 9619.

[3] B. J. B. Folmer, E. Cavini, R. P. Sijbesma, E. W. Meijer, Chem. Commun. 1998, 1847.; J. J. D. de Jong, L. N. Lucas, R. M. Kellogg, J. H. van Esch, B. L. Feringa, Science 2004, 304, 278.

[4] Y. Liu, A. H. Flood, J. F. Stoddart, J. Am. Chem. Soc. 2004, 126, 9150; J. P. Sauvage, Chem. Commun. 2005, 1507.

[5] D. B. Smithrud, F. Diederich, J. Am. Chem. Soc. 1990, 112, 339.

[6] D. J. Cram, H. J. Choi, J. A. Bryant, C. B. Knobler, J. Am. Chem. Soc. 1992, 114, 7748; J. C. Nelson, J. G. Saven, J. S. Moore, P. G. Wolynes, Science 1997, 277, 1793. 
[7] K. T. Chapman, W. C. Still, J. Am. Chem. Soc. 1989, 111, 3075; Y. Tokunaga, D. M. Rudkevich, J. Santamaria, G. Hilmersson, J. Rebek, Jr., Chem. Eur. J. 1998, 4, 8; R. K. Castellano, R. Clark, S. L. Craig, C. Nuckolls, J. Rebek Jr., Proc. Natl. Acad. Sci.USA 2000, 97, 12418; D. Lopez, J.-M. Guenet, Macromolecules 2001, 34, 1076; A. Scarso, L. Trembleau, J. Rebek Jr., J. Am. Chem. Soc. 2004, 126, 13512.

[8] L. Bouteiller, O. Colombani, F. Lortie, P. Terech, J. Am. Chem. Soc. 2005, 127, 8893.

[9] In fact, rheological experiments show that the toluene solution is a Maxwellian viscoelastic fluid, ${ }^{[10]}$ whereas the 1,3,5-trimethylbenzene solution is a purely Newtonian fluid of moderate viscosity (G. Ducouret, unpublished results).

[10] F. Lortie, S. Boileau, L. Bouteiller, C. Chassenieux, B. Demé, G. Ducouret, M. Jalabert, F. Lauprêtre, P. Terech, Langmuir 2002, 18, 7218.

[11] We define the length (L), the width (W) and the thickness (Th) of the solvent molecules as the respective dimensions of the smallest right-angled parallelepiped containing the molecule, such that $\mathrm{L} \geq \mathrm{W} \geq \mathrm{Th}$. Geometry optimization was performed through semiempirical calculations with AM1 method using the software Hyperchem 7.5 (Hypercube, Inc.).

[12] A. Scarso, L. Trembleau, J. Rebek Jr., Angew. Chem. Int. Ed. 2003, 42, 5499; Angew. Chem. 2003, 115, 5657; D. Rechavi, A. Scarso, J. Rebek Jr., J. Am. Chem. Soc. 2004, 126, 7738; L. C. Palmer, J. Rebek Jr., Org. Lett. 2005, 7, 787.

[13] P. Terech, R. G. Weiss, Chem. Rev. 1997, 97, 3133.

[14] A. Arnaud, L. Bouteiller, Langmuir 2004, 20, 6858. 
Table 1 Transition temperature between the thin and thick filaments for EHUT solutions in aromatic solvents $(12.5 \mathrm{mM})$

\begin{tabular}{|c|c|}
\hline Solvent & $\mathrm{T}^{* *} /{ }^{\circ} \mathrm{C}$ \\
\hline$n$-butylbenzene & 51.7 \\
\hline$p$-xylene & 49.5 \\
\hline 1,4-diethylbenzene & 49.2 \\
\hline$t$-butylbenzene & 49.1 \\
\hline ethylbenzene & 43.5 \\
\hline toluene & 43 \\
\hline$o$-xylene & 38.3 \\
\hline$m$-xylene & 34.2 \\
\hline 3-ethyltoluene & 34.2 \\
\hline 1,2,4-trimethylbenzene & 34.1 \\
\hline 1,3-diisopropylbenzene & 32.1 \\
\hline 1,3-dimethyl,5-t-butylbenzene & 23.9 \\
\hline 1,3,5-trimethylbenzene (TMB) & 13.4 \\
\hline 1,3,5-triisopropylbenzene & $<-6$ \\
\hline
\end{tabular}

Scheme 1. Structure of bis-urea EHUT. 
a)

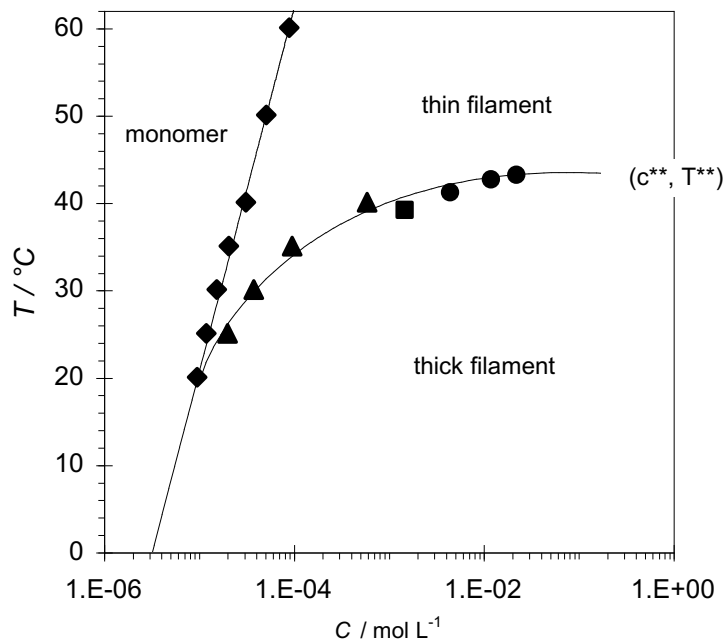

b)

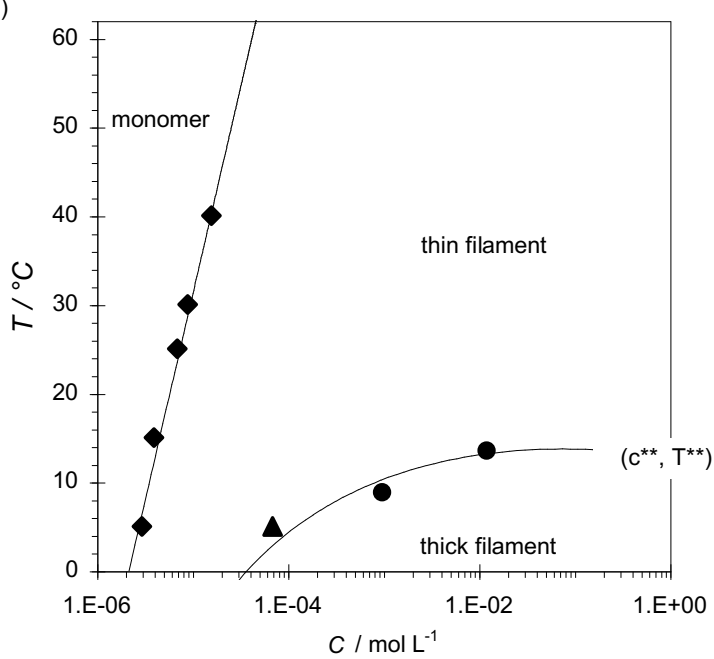

Figure 1. Pseudophase diagram for EHUT solutions in toluene (a) or TMB (b). Transition between monomer and thin supramolecular filament is determined by ITC $(\bullet)$. Transition between thin and thick supramolecular filament is determined by $\operatorname{ITC}(\mathbf{\Delta})$, viscosimetry $(\mathbf{\square})$ or $\operatorname{FTIR}(\bullet)$. 
a)

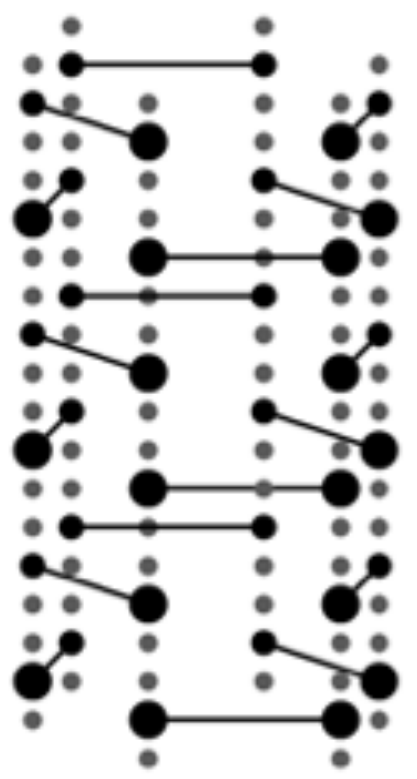

b)

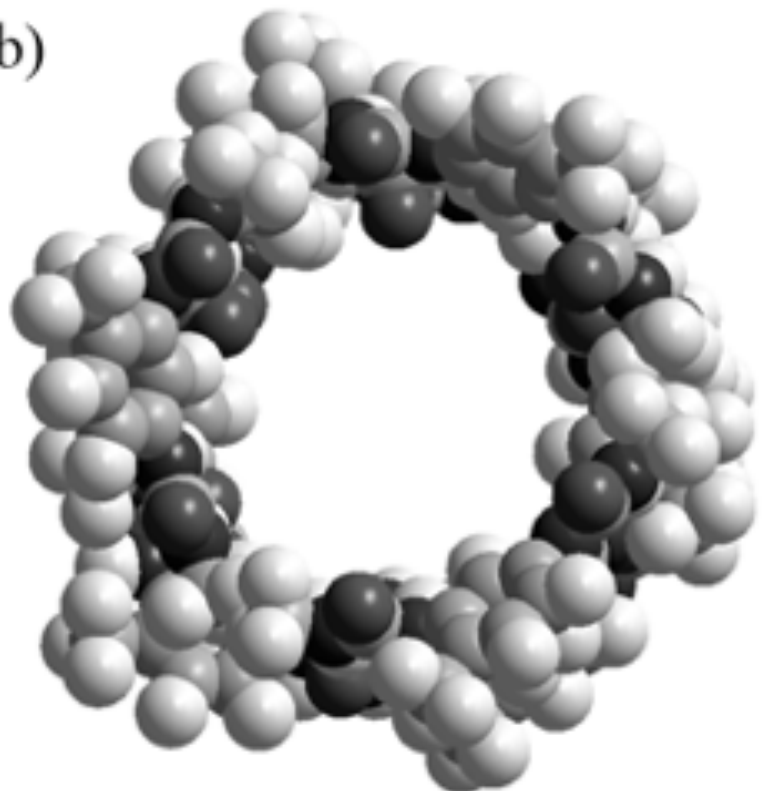

Figure 2. Schematic trimolecular arrangement proposed (hydrogen bonds are symbolized by dotted lines connecting urea functions) (a) and top view of this arrangement (minimized with Hyperchem software) (b). 

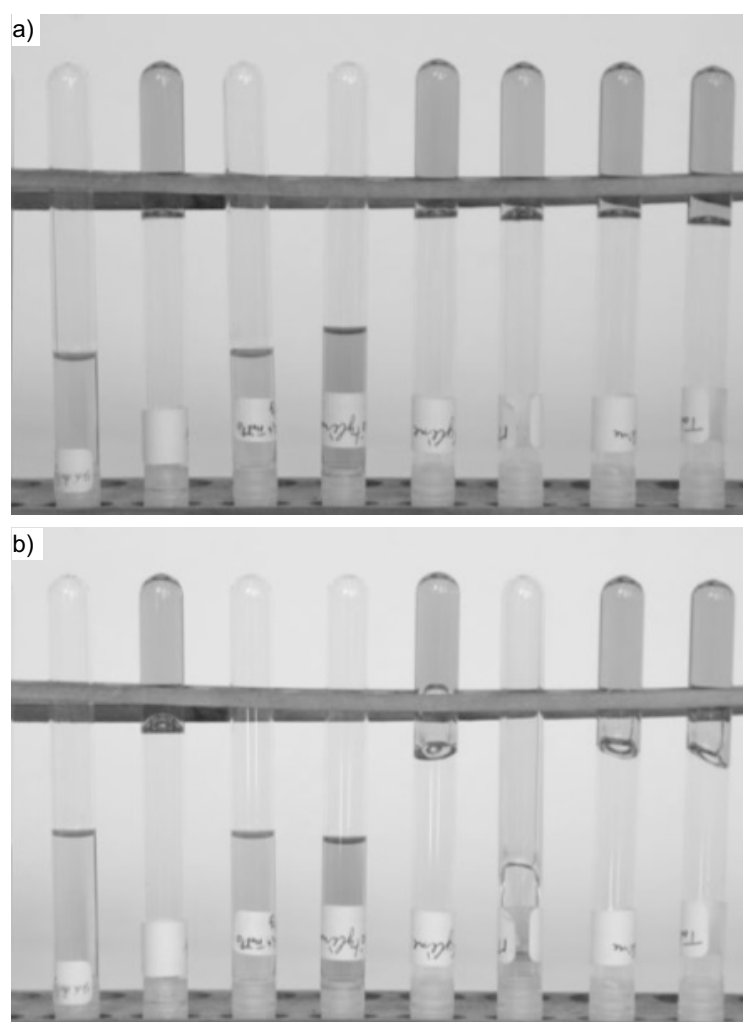

c)
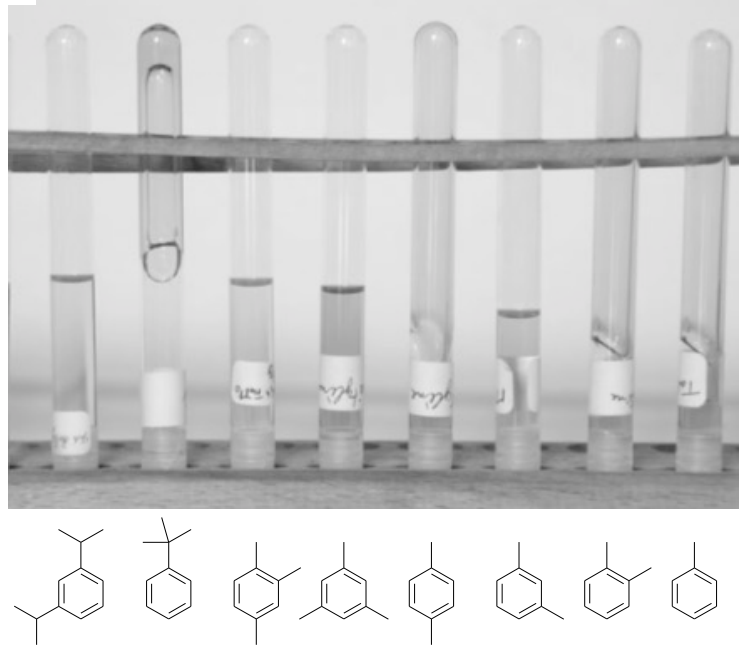

Figure 3. EHUT solutions in several aromatic solvents (12.5 $\mathrm{mM}$ at room temperature). The photographs were taken immediately (a), 7 minutes (b) or 40 minutes (c) after inverting the test tubes. 

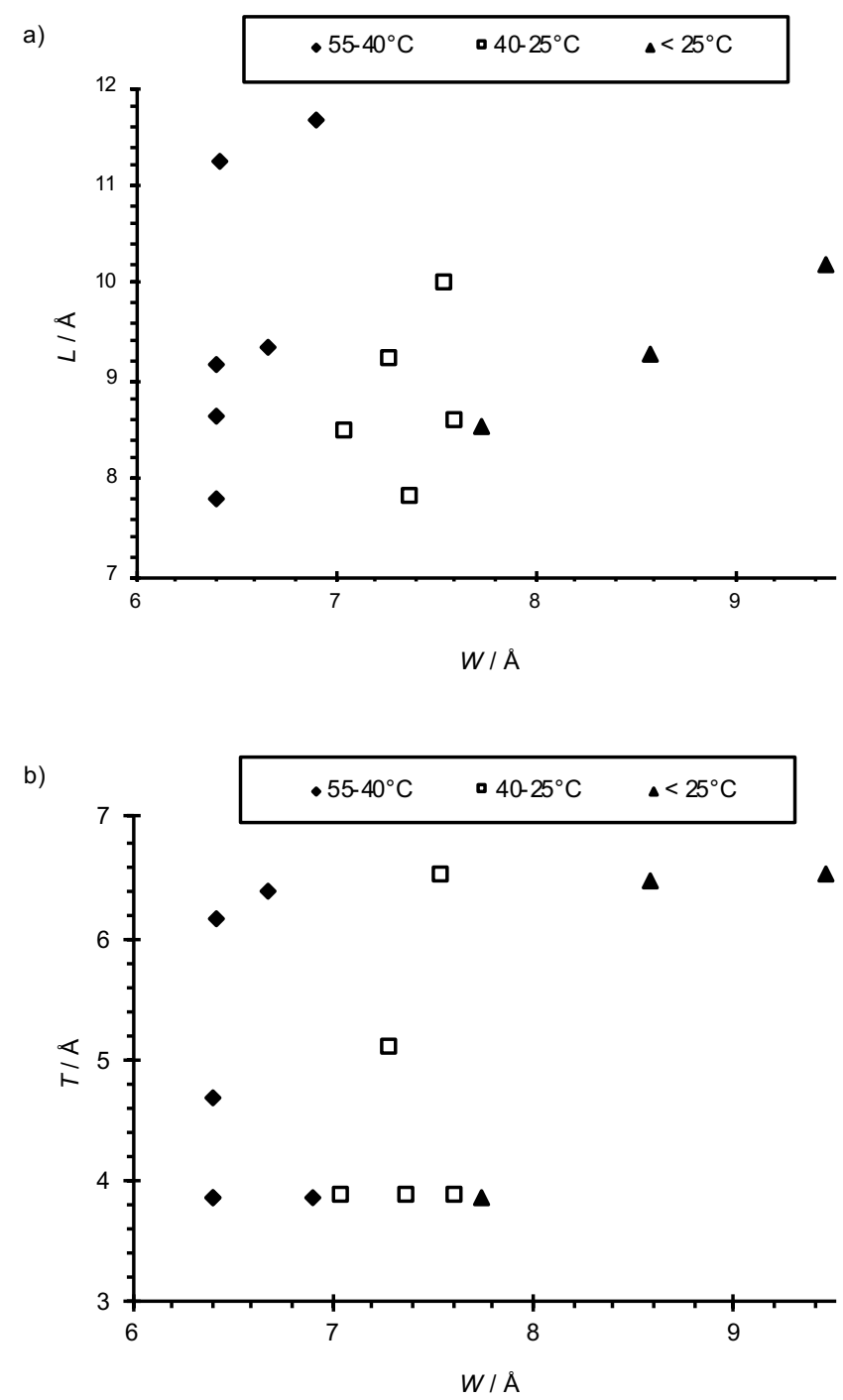

Figure 4. Transition temperature $\left(\mathrm{T}^{* *}\right)$ between the thin and thick filaments for EHUT solutions in aromatic solvents, versus length (L), width (W) and thickness (Th) of the solvent molecules. ${ }^{11}$ 